\title{
PRODUÇÃO MAIS LIMPA NO SETOR DE CACHAÇA: ESTUDO EM ENGENHO NO ESTADO DA PARAÍBÁ
}

\author{
CLEANER PRODUCTION IN CACHAÇA SECTOR:
} STUDY IN ENGENHO IN THE STATE OF PARAÍBA

Recebido em 11.12.2017. Aprovado em 02.02.2018
Avaliado pelo sistema double blind review
DOI: http://dx.doi.org/10.12712/rpca.v12i1.1146

\section{Maria Angélica Pompéu da Fonseca}

fonseca.angelica@yahoo.com.br

Universidade Federal de Campina Grande (UFCG), Campina Grande/PB, BRASIL

\section{Maria de Fátima Martins}

fatimamartins2005@gmail.com

Universidade Federal de Campina Grande (UFCG), Campina Grande/PB, BRASIL

\begin{abstract}
Resumo
A Produção mais Limpa (PL) busca minimizar os impactos que as organizações podem causar ao meio ambiente, através da redução dos resíduos no processo produtivo. Neste sentido, o estudo objetiva averiguar as práticas da produção mais limpa para minimização de resíduos do processo produtivo de um engenho produtor de cachaça, localizado no Município de Areia - PB. A pesquisa é classificada como descritiva, sendo um estudo de caso utilizando como base os três níveis da PL proposto pelo Conselho Nacional de Tecnologias Limpas - CNTL (2003). A coleta de dados ocorreu através de entrevista semi estruturada com o proprietário do engenho e da observação direta através de visitas técnicas. As informações coletadas foram analisadas de forma qualitativa. Os resultados identificaram que no nível I - Redução na fonte é o menos presente nas práticas do engenho, isso ocorre em função da impossibilidade de evitar a geração dos resíduos nesse tipo de produção; o nível II - Reciclagem Interna possui maior destaque dentre os níveis, cujos resíduos gerados são em sua maioria reciclados e utilizados no processo próprio produtivo. No nível III - destaca-se a reciclagem externa do bagaço e a compostagem orgânica da palha.
\end{abstract}

Palavras-chave: Gestão Ambiental. Produção mais Limpa. Produção da cachaça.

\section{Abstract}

The Cleaner Production has as objective to perform measures which can reduce the impact that organizations can have on the environment, through the reduction of waste in the production process. In this manner, this study aims to investigate the practices of cleaner production to minimizing the resultant sediments in production of cachaça at the city of Areia - PB. This research is classified as a case study and descriptive, using as a basis the three levels of PML proposed by the National Council for Clean Technology - CNTL (2003). The data collection was made through semi structured interviews with the owner of engenho and direct observation in visits to it. The information collected were studied by qualitative analysis. The results showed that the level I - Reduction at source is the least present, therefore, there is the possibility to avoid generating residues; e the level II - Internal Recycling has greater prominence among the levels; so waste generated are mostly used in the production process. The level III - there is the external recycling and organic compost mulch of straw.

Keywords: Environmental Management, Cleaner Production. Production of Cachaça. 


\section{Introdução}

A partir do processo de industrialização, houve na sociedade um aumento considerado da produção e do consumo de bens, tendo como consequência maior utilização dos recursos naturais e aumento dos resíduos gerados no planeta. Com isto, quando o homem passou a perceber que os recursos proporcionados pela natureza eram limitados, procurou desenvolver técnicas e medidas capazes de racionalizar o uso de tais recursos, seja através do controle, da conscientização e de formas mais adequadas de gerenciamento.

Nesta perspectiva, as empresas que são grandes responsáveis por utilizar de forma desenfreada os recursos naturais, tais como, água e energia, se mobilizaram em busca de uma gestão, a qual fosse capaz de reduzir os custos e aumentar sua lucratividade sem agredir ao meio ambiente. Neste sentido, a gestão ambiental passou a auxiliar as organizações, no sentido de possibilitar a incorporação e desenvolvimento de boas práticas com formas adequadas que minimizam os impactos no meio ambiente (DRUNN; GARCIA, 2011).

Uma das ferramentas propostas pela gestão ambiental é a Produção Mais Limpa, a qual proporciona à organização não apenas reduzir seus custos, mas principalmente fazer uso eficiente de seus recursos, uma vez que, para uma melhor aplicação desta ferramenta a empresa deve analisar a geração dos resíduos em todo o processo produtivo, pois muitas vezes a geração exagerada de resíduos é ocasiona por layout inadequado, procedimentos de trabalho, manuseio de equipamentos ou ferramentas, entre outros. Sendo assim, a prevenção na geração dos resíduos é um dos pilares que sustenta esta ferramenta, visto que, o seu objetivo estar em evitar ao máximo à geração de resíduos e caso isso seja inevitável, buscar meios adequados para o seu descarte, através da reciclagem interna ou externa.

Nesses termos, a implementação de um Programa de Produção Mais Limpa proporciona à organização um conhecimento preciso em relação ao seu processo industrial através da observação constante para a manutenção e desenvolvimento de um sistema ecoeficiente de produção com a geração de indicadores ambientais e de processo, sendo estes capazes de aperfeiçoar todos os recursos produtivos (CNTL, 2003). Destarte, a Produção Mais Limpa pode ser aplicada em qualquer setor, desde que a empresa seja flexível quanto ao seu modo de gerir seus processos, pois para sua implementação faz-se necessário o comprometimento de todos da organização, devido ser uma prática que deve ser monitorada constantemente e que exige de todos uma consciência ambiental, desenvolvida na própria organização.

Nesta perspectiva, o setor sucroalcooleiro é um dos setores que é possível realizar a aplicação desta ferramenta, em função de sua representatividade na economia nacional e dos impactos ambientais que a atividade pode gerar. Este setor é responsável pela produção do açúcar e álcool, sendo um dos maiores existente no Brasil, responsável por alavancar de forma significativa sua economia (VIEIRA; LIMA; BRAGA, 2007). Os produtos oferecidos por este setor são provenientes da cana de açúcar, matéria prima muito representativa na economia nacional, cujo produto de maior destaque é a cachaça. De acordo com a Associação Brasileira de Bebidas (ABRABE) a cachaça é um produto tipicamente brasileiro e que atualmente vem sendo apreciada cada vez mais pelos consumidores internacionais, caracterizando-o como o terceiro maior destilado do mundo, representando $50 \%$ do volume de produção de destilados.

São vários os estados brasileiros produtores da cachaça, dentre eles, destaca-se: São Paulo como sendo o maior produtor; seguido de Pernambuco, Ceará, Minas Gerais e Paraíba, respectivamente. Sendo este último, responsável por sediar as principais empresas de cachaça de alambique do país, gerando emprego e movimentando a economia de diversos municípios, dentre eles Areia-PB, localizada na região do brejo, onde possui mais de 20 engenhos produtores de cachaça, mel e rapadura. (EMBRAPA, 2010).

Diante das considerações, o presente estudo tem como objetivo averiguar as práticas da produção mais limpa para minimização de resíduos do processo produtivo de um engenho produtor de cachaça localizado no Município de Areia - PB. A relevância do artigo consiste em mostrar a aplicação dos conceitos de produção mais limpa no setor produtor de cachaça, e de forma prática, apontar a melhor forma de gerenciar os resíduos do processo produtivo, no sentido de reduzir o impacto ambiental dessa atividade econômica.

$\mathrm{O}$ artigo encontra-se estruturado com essa parte introdutória, seguido da base teórica que deu embasamento ao estudo, seja, aspectos da gestão ambiental e a produção mais limpa; os aspectos metodológicos; os resultados referentes aos resíduos e os aspectos da produção mais limpa no Engenho em estudo; e por fim, as considerações finais e as referências bibliográficas. 


\section{Fundamentação teórica}

\section{Conceitos e Ferramentas da Gestão Ambiental}

Foi a partir da Revolução Industrial que os problemas relacionados ao meio ambiente ganharam uma maior percepção por parte dos governantes, empresas e a população, pois, com a indústria trabalhando de maneira acelerada emitindo substâncias tóxicas e ácidas, bem como, gases de efeito estufa ocasionou o aparecimento de substancias jamais encontradas na natureza, substâncias estas que poderiam comprometer os recursos naturais e as gerações seguintes (BARBIERI, 2004).

Quando se trata das questões ambientais, as empresas estão sendo cada vez mais cobradas quanto aos seus atos e postura. Sendo assim, estão buscando adotar práticas que possam reduzir os impactos no meio ambiente e, ao mesmo tempo, aumentar sua competitividade, já que as ações efetuadas impactam diretamente na sociedade, e esta por sua vez está procurando exigir cada vez mais das organizações ações socioambientais. De tal modo, como destaca Borger (2001) as empresas estão tendo que competir em um ambiente de negócios cada vez mais complexo, no qual não é mais suficiente apenas atender as leis e pagar impostos, oferecer qualidade e preço competitivo, devendo estar atentas aos impactos que suas ações podem causar aos seus stakeholders, incluindo o meio ambiente e a sociedade.

Deste modo, a Gestão Ambiental tornou-se uma grande aliada aos executivos, uma vez que fornece um leque de possibilidades e ferramentas capazes de proporcionar às organizações meios para melhorar sua gestão, diminuindo os impactos ambientais, otimizando os recursos e aumentando sua competitividade. De acordo com Lanna (1995) a gestão ambiental consiste no processo de mobilização dos agentes sociais, tais como governo, empresa e sociedade, cujo objetivo é elaborar medidas as quais possam propiciar a exploração dos recursos naturais, econômicos e socioculturais de forma adequada, de maneira a atender as especificidades do meio ambiente.

A gestão ambiental destina-se a fazer com que as atividades humanas sejam eficientes quanto ao uso dos recursos, de forma que gere o menor impacto possível ao meio ambiente, visto que, tal eficiência é ocasionada pela administração dos recursos humanos e financeiros, a escolha das melhores técnicas e o cumprimento das leis estabelecidas pelos órgãos ambientais (AMBIENTE BRASIL, 2015). Esse tipo de gestão procura desenvolver técnicas capazes de adequar às ações que antes eram realizadas apenas com foco em seus resultados financeiros, incluindo as exigências que são relevantes para melhoria do meio ambiente. Deste modo, a gestão ambiental possui vários tipos de instrumentos e ferramentas para se chegar ao objetivo de preservação, monitoramento e melhoria do meio ambiente, dentre eles destacam-se os seguintes: Avaliação do Ciclo de Vida, Ecoeficiência, Ecodesign, Auditoria Ambiental, Educação Ambiental Empresarial, Rotulagem Ambiental e a Produção mais Limpa (PL), objeto do presente estudo.

\section{Produção mais Limpa}

O modelo de Produção mais Limpa (PL) vem sendo desenvolvido desde os anos 80 pelo PNUMA e pela Organização das Nações Unidas para o Desenvolvimento Industrial - ONUDI, agência que coordena os Centros Nacionais de Produção Mais Limpa que funcionam em dez países: Brasil, Hungria, China México, Índia, República Eslovaca, República Tcheca, Tunízia, Tanzânia e Zimbábue (BARBIERI, 2007 apud GONÇALVES, 2014).

A produção mais limpa é um modelo cuja finalidade é a prevenção para a não geração dos resíduos, haja vista que quando os resíduos não são gerados não há necessidade de preocupação com o seu destino. Esta técnica de prevenção foi reconhecida na Conferência Rio 92, como um dos principais meios para o desenvolvimento sustentável. Porém, o programa tomou destaque no Brasil em julho de 1995 com a implantação do Centro Nacional de Produção mais Limpa em Porto Alegre - RS no Serviço Nacional de Aprendizagem Industrial - SENAI (CNTL, 2003).

A partir de 1998, o CNTL-SENAI/RS e o CEBDS (Conselho Empresarial Brasileiro para o Desenvolvimento Sustentável), em parceria com o SEBRAE Nacional e outras instituições, iniciaram o desenvolvimento da Rede Brasileira de Produção mais Limpa, com o intuito de repensar a relação entre o processo produtivo e o meio ambiente, considerando o aumento da ecoeficiência e da produtividade (KIPERSTOK, Asher, et al. 2002) nos setores econômicos.

Nessa perspectiva, a PL é uma metodologia que busca identificar como, por que e onde surgem os resíduos, levando as empresas a identificar a melhor forma 
para gerenciá-los. É importante ressaltar que para a implementação da metodologia, a empresa deve estar disposta a possíveis modificações, seja no processo, na tecnologia ou até mesmo nas atitudes de seus funcionários. Como o modelo de PML é uma estratégia continuada e requer uma integração de todos os indivíduos, é importante que haja consenso entre eles, bem como, abertura por parte dos executivos para que todos se sintam a vontade em expor suas ideias e opiniões a respeito de como melhorar o processo. Sendo assim, BARBIERI (2004) destaca claramente um dos documentos elaborado pelo PNUMA, o qual afirma que, para se adotar a ferramenta da $\mathrm{P}+\mathrm{L}$ é necessária colocar em prática a criatividade existente em cada ser humano, pois é a partir desta que surgirão ideias capazes de modificar e solucionar o problema existente no processo, no serviço ou no descarte final do produto.

O CNTL (2003) traz uma visão mais ampla sobre a produção mais limpa, conceituando como uma estratégia capaz de aumentar a eficiência na utilização dos materiais e insumos utilizados no processo produtivo, a partir da reciclagem, minimização e se possível não geração dos resíduos e efluentes, cujos resultados podem proporcionar vários benefícios à empresa, sociedade e meio ambiente. A partir deste conceito observa-se que a $\mathrm{P}+\mathrm{L}$ é uma estratégia que pode ser adotada pelas organizações através da eficiência em seus processos, visando alinhar as metas organizacionais ao desenvolvimento sustentável, resultando em melhor competitividade no mercado.

Conforme o CNTL (2003) as ações da P+L são separadas em três níveis, o primeiro relacionado as ações que podem ser realizadas dentro da organização - minimização da geração de resíduos e emissões, sendo prioridade máxima da $\mathrm{P}+\mathrm{L}$, pois o mesmo se trata de evitar a geração de resíduos na fonte, seja através da modificação no produto ou no processo, podendo ser realizada a substituição da matériaprima utilizada ou a modificação dos seus recursos tecnológicos. Quando não é possível evitar a geração de resíduos na fonte, parte-se para o segundo nível, cujo objetivo é a reciclagem interna, ou seja, reutilização dos resíduos dentro da própria organização. O outro grupo caracteriza-se como sendo o reuso de resíduos, efluentes e emissões, que é representado pelo nível 3 , cuja finalidade é a reciclagem externa ou os ciclos biogênicos, a primeira ocorre quando os resíduos não serão mais aproveitados pela organização e a mesma decide vender ou doar tais resíduos para que outras empresas reciclem, já a segunda ocorre quando não é possível reciclar e os mesmos serão destinados a uma finalização segura sem impactos ao ao meio ambiente. Vide Figura 1 apresentada pelo CNTL (2003):

Figura 1. Níveis de Produção Mais Limpa

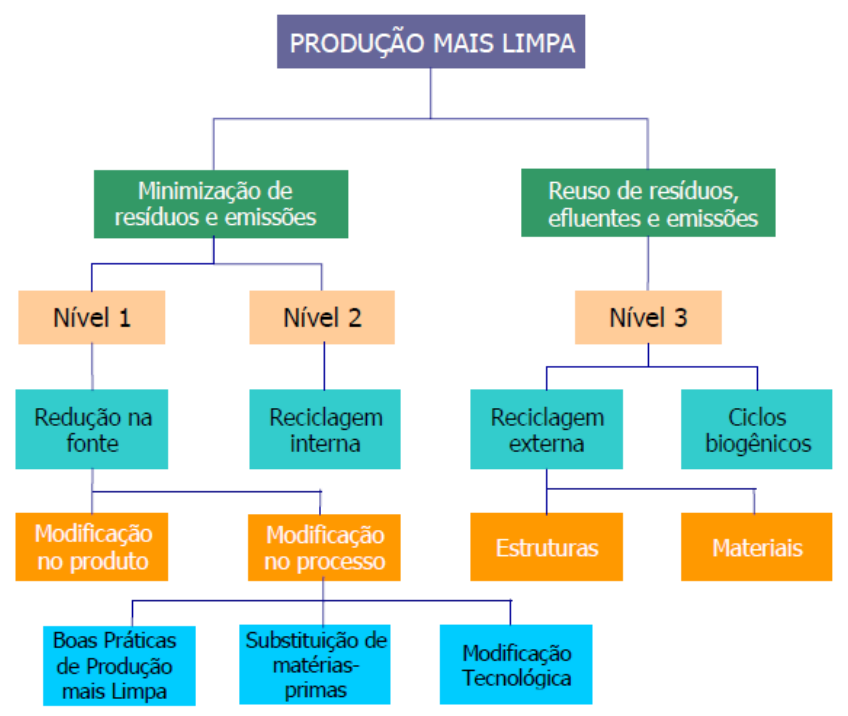

Fonte: CNTL/SENAI(2003)

Diante disto, observa-se que são várias as vantagens em se implementar a metodologia da Produção mais limpa, tais como: redução dos resíduos e emissões de poluentes, limitação da responsabilidade na destinação dos resíduos para o meio ambiente, redução dos custos de gerenciamento dos resíduos, melhoria na imagem da organização e etc.

Destarte, a implementação da produção mais limpa é viável em qualquer setor e/ou organização, desde que esta seja passível de mudanças, uma vez que a $\mathrm{P}+\mathrm{L}$ busca fazer uma análise da situação da empresa com o intuito de enquadrar suas respectivas ações à realidade da mesma, buscando melhorias econômicas, sociais e ambientais através da redução e emissão de resíduos e poluentes. Sendo assim, o setor de cachaça é um dos principais setores brasileiros que está buscando renovar suas tecnologias e seus processos, com o intuito de otimizar a sua produção e atender as exigências ambientais, econômicas e sociais, com isso será apresentado a seguir este setor, objeto do presente estudo. 


\section{Setor de Cachaça}

A cachaça é uma bebida adquirida a partir do mosto fermentado da cana de açúcar (LIMA et al., 2006), estando respaldada pela Lei $\mathrm{n}^{\circ}$ 8.918, de 14 de julho de 1994 e o Decreto no 6.871, de 4 de junho de 2009, que a regulamenta e dispõe sobre a padronização, classificação, registro, inspeção, produção e a fiscalização de bebidas.

De acordo com a ÚNICA, o Brasil é o maior produtor da cana de açúcar do mundo, a qual tem sua produção distribuída por todo o país, concentrandose principalmente no centro-sul e norte-nordeste, o maior exportador de açúcar mundial de acordo com a United States Department of Agriculture (USDA) e o segundo maior produtor de etanol do planeta, segundo a F.O.Licht (BIOSEV, 2015).

A cachaça é a terceira bebida destilada mais consumida no ranking mundial e a primeira no Brasil. De acordo com o Programa Brasileiro de Desenvolvimento da Aguardente de Cana (PBDAC), a produção ocorre em torno de 1,2 bilhões de litros por ano, sendo que cerca de $75 \%$ desse total é representada pela fabricação industrial e $25 \%$, é decorrente da fabricação artesanal. Deste volume, cerca de 14,8 milhões de litros são exportados; sendo a maior parte para a Europa, principalmente para a Alemanha, que consome mais de $30 \%$ do total exportado (SAKAI, 2010).

Segundo o Sistema de Controle da Produção de Bebidas da Receita Federal (SICOBE) em 2013 o faturamento do setor alcançou $\mathrm{R} \$ 5,95$ bilhões, decorrentes da produção de 511,54 milhões de litros da bebida. De acordo com o Instituto Brasileiro da cachaça (IBRAC) o Brasil possui cerca de 40 mil produtores espalhados por todo o país, sendo apresentadas em torno de 4 mil marcas de cachaça. Tais produtores localizam-se nos seguintes estados: São Paulo, Pernambuco, Ceará, Rio de Janeiro, Minas Gerais, Goiás, Paraná, Paraíba e Bahia.

A produção de Cachaça na Paraíba concentra-se principalmente na microrregião do Brejo e mesorregião do Agreste, estando os maiores produtores de cachaça de alambique localizados na cidade de Areia$\mathrm{PB}$, contendo em torno de 20 engenhos fabricantes de cachaça, mel e rapadura, em sua maioria esses engenhos possuem mais de 200 anos de existência. O maior engenho da cidade de Areia produz cerca de 420 mil litros por ano e nos demais, a produção chega em torno de 180.000 mil litros de cachaça. Essa atividade econômica constitui oportunidades de emprego e renda para a população local, uma vez que a menor empresa conta com uma quantidade de 5 funcionário, enquanto que a maior possui 52 empregados, nos demais engenhos a quantidade de funcionários varia entre 8 a 15 pessoas (BARROS; MACÊDO, 2011).

Vale ressaltar que a fabricação de cachaça lida diretamente com o meio ambiente, pois embora a maioria dos produtores desta região se caracterize como pequenos e médios, todos realizam o plantio e a colheita para produzir sua cachaça, visto que a produção desta, faz o uso exagerado de água e energia, pois são itens primários no processo de fabricação. Portanto, nota-se que o modelo de Produção mais Limpa é viável para este setor, uma vez que é capaz de proporcionar análise quanto ao uso adequado da água, energia e demais recursos da produção, além de buscar gerenciar os resíduos, vistos como importantes componentes do processo produtivo, tendo como consequência a não degradação ao meio ambiente, a diminuição dos custos e uma maior competitividade no mercado.

\section{Metodologia}

Para a realização deste estudo foi realizada a pesquisa bibliográfica com uma revisão da literatura relacionada a Produção mais Limpa, abordando os conceitos e metodologias; e os aspectos do setor produtivo da cachaça.

Este estudo caracteriza-se como descritivo, pois conforme é ressaltado por Gil (1999) este tipo de pesquisa busca descrever as características dos fenômenos existentes ou definir as relações entre as variáveis estabelecidas. Além disso, a pesquisa pode ser definida como qualitativa, pois de acordo com Godoy (1995) pesquisas do tipo qualitativa apresentamse da seguinte forma: o pesquisador é considerado um instrumento chave e o ambiente estudado é um meio direto para se obter as informações desejadas, os métodos e as técnicas estatísticas são irrelevantes, deve-se atentar para a interpretação dos fenômenos e com os dados obtidos deve ser realizada uma análise intuitiva e indutiva.

De tal modo, a presente pesquisa buscou identificar os aspectos da produção mais limpa, tomando como base um conjunto de variáveis estabelecidas pelo CNTL (2003), considerando os três níveis propostos 
pela ferramenta da gestão ambiental, a Produção Mais Limpa.

Quadro 1. variáveis da pesquisa

\begin{tabular}{|c|c|c|}
\hline \multicolumn{3}{|c|}{ NÍVEIS DOS RESÍDUOS GERADOS } \\
\hline $\begin{array}{l}\text { NÍVEL DE } \\
\text { REDUÇAO DE } \\
\text { RESÍDUOS }\end{array}$ & PRÁTICA & VARIÁVEL \\
\hline \multirow[t]{4}{*}{$\begin{array}{c}\text { Nível } 1 \\
\text { Redução na fonte }\end{array}$} & $\begin{array}{l}\text { Modificação } \\
\text { do produto }\end{array}$ & $\begin{array}{l}\text { Substituição e } \\
\text { Composição do } \\
\text { produto }\end{array}$ \\
\hline & \multirow[t]{3}{*}{$\begin{array}{l}\text { Modificação } \\
\text { do processo }\end{array}$} & $\begin{array}{c}\text { Boas práticas de } \\
\text { Produção Mais } \\
\text { Limpa }\end{array}$ \\
\hline & & $\begin{array}{l}\text { Substituição de } \\
\text { matérias primas }\end{array}$ \\
\hline & & $\begin{array}{l}\text { Modificação } \\
\text { tecnológica }\end{array}$ \\
\hline \multirow[t]{2}{*}{$\begin{array}{l}\text { Nível } 2 \\
\text { Reciclagem } \\
\text { interna }\end{array}$} & \multirow[t]{2}{*}{$\begin{array}{l}\text { Reciclagem } \\
\text { interna }\end{array}$} & $\begin{array}{c}\text { Reintegração do } \\
\text { resíduo no processo } \\
\text { produtivo }\end{array}$ \\
\hline & & $\begin{array}{l}\text { Reutilização na } \\
\text { produção de sub } \\
\text { produto }\end{array}$ \\
\hline \multirow{4}{*}{$\begin{array}{c}\text { Nível } 3 \\
\text { Reciclagem } \\
\text { externa e ciclos } \\
\text { biogênicos }\end{array}$} & \multirow[t]{2}{*}{$\begin{array}{l}\text { Reciclagem } \\
\text { externa }\end{array}$} & \begin{tabular}{|c} 
Materiais vendidos/ \\
doados para \\
reciclagem
\end{tabular} \\
\hline & & $\begin{array}{l}\text { Coleta, seleção e } \\
\text { armazenamento dos } \\
\text { resíduos }\end{array}$ \\
\hline & \multirow[t]{2}{*}{$\begin{array}{l}\text { Ciclos } \\
\text { biogênicos }\end{array}$} & $\begin{array}{l}\text { Compostagem } \\
\text { orgânica ou adubo } \\
\text { para o solo }\end{array}$ \\
\hline & & $\begin{array}{c}\text { Recuperação de } \\
\text { energia ou material }\end{array}$ \\
\hline $\begin{array}{l}\text { Alternativa final: } \\
\text { destino dos } \\
\text { resíduos }\end{array}$ & $\begin{array}{l}\text { Disposição } \\
\text { adequada dos } \\
\text { resíduos }\end{array}$ & $\begin{array}{l}\text { Destino Final dos } \\
\text { resíduos }\end{array}$ \\
\hline
\end{tabular}

Fonte: Elaborado com base na metodologia de PML - CNTL (2003).

Para ser possível a aplicação desta ferramenta no engenho produtor de cachaça foi realizada uma adequação, tendo como base questões as quais pudessem alcançar os objetivos de cada um dos níveis mencionados.

Quanto a Unidade de Análise e sujeitos da pesquisa, a pesquisa foi realizada em um engenho produtor de cachaça, localizado na zona rural do Município de Areia - PB, fabricante da cachaça Ipueira. A pesquisa só pôde ser realizada devido a colaboração do proprietário do engenho através das informações fornecidas, além disso, ocorreram visitas in loco para acompanhar o processo de produção, auxiliando assim na complementação dos dados referentes aos aspectos da ferramenta incorporados no processo produtivo.

A coleta de dados para obtenção dos resultados do estudo ocorreu através da observação direta, que de acordo com Marconi e Lakatos (2002) pode ser definida como um meio para se obter informações da realidade do local através dos sentidos, os quais não se resume a apenas ver e ouvi, como também analisar os fatos que se pretende estudar. Este meio para coletar os dados se realizou através de visitas ao engenho, nos meses de julho e agosto de 2015, tal visita proporcionou a identificação dos aspectos da Produção Mais Limpa presentes no processo produtivo da cachaça Ipueira. Com as visitas, realizou-se também a entrevista com o proprietário da empresa, guiada por um instrumento semi-estruturado. O instrumento utilizado para a obtenção dos dados junto à empresa foi um formulário elaborado com base o modelo metodológico de implantação da Produção mais Limpa, elaborado pelo Centro Nacional de Tecnologias Limpas - CNTL (2003).

Em relação ao tratamentorealizado com as informações levantadas, pode-se afirmar que o mesmo ocorreu de forma qualitativa, buscando detectar a existência dos aspectos referentes a Produção mais limpa, a partir dos níveis, práticas e variáveis estudados. De tal modo, a partir das informações fornecidas pela empresa, da observação direta ao processo de produção de cachaça e da percepção dos pesquisadores quanto ao fenômeno investigado foi possível estabelecer as análises e as conclusões do estudo.

\section{Resultados e discussão}

O Engenho estudado localiza-se na zona rural da cidade de Areia-PB situada na região do brejo paraibano, estando à $129 \mathrm{~km}$ de distância da capital João Pessoa. Inicialmente, a sua produção consistia na fabricação de rapadura, produto em forma de tablete obtido a partir da concentração quente do caldo da cana. Porém, com o passar dos anos a demanda foi diminuindo e o proprietário observou que não estava havendo lucro para o engenho, foi então que há cerca de 12 anos começou-se a produção de cachaça, comercializada do tipo a granel. Com a alta demanda e a aceitação no mercado, a partir de 2009 começou 
a ser realizado o engarrafamento da cachaça em dois diferentes tipos, a cristal e a umburana, embaladas em garrafas de diferentes tipos e tamanhos. A cristal em garrafa âmbar, que conserva e protege melhor o produto, tendo o tamanho de $355 \mathrm{ml}$, e a cachaça com o sabor de umburana, colocadas em garrafas transparentes, devido a necessidade de mostrar a cor do produto ao cliente, cujo tamanho é de $275 \mathrm{ml}$. A venda destes produtos gira em torno de 48.000 garrafas por mês. Além desses dois tipos, atualmente estão produzindo a cachaça de carvalho, ainda não sendo comercializada, pois a mesma necessita de um tempo maior para o envelhecimento nos barris de carvalho, adquirindo assim, o gosto e a cor deste tipo de bebida, podendo ser comparada aos tradicionais whiskys. Sendo estas, formas encontradas pelos Engenhos para diferenciação da cachaça no mercado e diversificação dos produtos oferecidos.

\section{Processo Produtivo}

O período de produção de cachaça nos engenhos está diretamente ligado ao clima e ao período chuvoso que não favorece a produção de cana-de açúcar, uma vez que este é um dos fatores que influencia diretamente na qualidade e produtividade da cana. O período que favorece fortemente a plantação da cana é entre os meses de agosto a abril, por estes serem os meses os quais não apresentam excesso de chuvas na região, fazendo com que o índice de sacarose presente na cana não seja afetado. A produção da cachaça é durante todo o ano, parando apenas aos domingos para limpeza das maquinas, bem como, nos meses de junho e julho para a manutenção das mesmas.

O processo produtivo da cachaça consiste nas seguintes etapas:

- Plantio e Colheita: A cana de açúcar é plantada e o tempo entre o plantio e a colheita é de aproximadamente 14 meses, sendo o tempo necessário para o ápice de maturação da cana para começar o corte da cana, não existindo a queima da palha que é deixada nos canaviais para adubar o solo. O corte é feito manualmente e transportado por animais para o local de moagem.

$\mathrm{Na}$ preparação do solo é utilizando adubo orgânico proveniente da palha deixada no solo, além de fertilizante químico para a preparação e as cinzas oriundas do bagaço utilizado no aquecimento das caldeiras.
- Moagem: Nesta etapa ocorre extração do caldo da cana, separando-o do bagaço, depois de extraído o caldo vai para a dorna de decantação (decantador) que comporta 1000 litros de caldo. Neste processo ocorre a filtração e a retirada de impurezas, diluindo o mesmo e nivelando o teor de açúcar para atingir o ideal que é 15 brix (o grau de brix é a quantidade de sólidos solúveis açucares totais) presente no caldo (FEAM, 2013).

- Fermentação: Nesta etapa acontece reações químicas, ou seja, com a ação de leveduras o mosto é transformado em álcool etílico e gás carbônico. O fermento utilizado é o fermento natural, proveniente do próprio caldo da cana, a partir do agente fermentativo presente, a microbiota natural. Esta etapa pode durar de 18 a 24 horas.

- Destilação: Neste processo são utilizados quatro alambiques de cobre, sendo dois pré-aquecedor e dois destiladores, os primeiros aquecem o caldo a uma temperatura de $80^{\circ} \mathrm{C}$, quando evaporado o mesmo passa por um sistema de resfriamento e é acondicionado nos destiladores para ser realizada a condensação e transformar o vapor em cachaça, a qual é separada em três partes: cabeça, coração e calda. Os primeiros $10 \%$ do destilado total corresponde a cabeça e o seu teor alcoólico é muito alto cerca de $60 \%$, portanto inapropriada para o consumo, sendo armazenada para ser utilizada na limpeza dos equipamentos ou para ser transformada em combustível. Em seguida retirase os $80 \%$ do destilado, sendo esta a parte nobre, ou seja, a cachaça própria para o consumo. E por fim, resta os $10 \%$ referente a calda, que por apresentar o teor alcoólico muito baixo é misturada a cabeça, para ser utilizada com as mesmas finalidades.

- Armazenamento/Envelhecimento: Este é realizado em três diferentes tipos, na dorna de plástico, no barril de umburana e no barril de carvalho. $\mathrm{Na}$ dorna de plástico é armazenada a cachaça cristal, permanecendo em descanso durante cerca de cinco meses, o mesmo ocorre com a cachaça em barril de umburana, que por ser armazenada em barril de madeira ganha a cor e o aroma diferenciado, e o armazenamento da cachaça de carvalho ocorre com a finalidade do envelhecimento da mesma, cujo barril é lacrado e datado pelo Ministério da Agricultura, sendo aberto apenas quando autorizado. Quanto ao envelhecimento, a Lei $\mathrm{n}^{\circ} 8.918$, de 14 de julho de 1994, Decreto no 6.871, de 4 de junho de 2009, 
determina que a cachaça envelhecida corresponde "a bebida que contiver, no mínimo, cinquenta por cento de aguardente de cana envelhecida por período não inferior a um ano".

- Engarrafamento: Antes de ser realizado o engarrafamento da cachaça, as garrafas (algumas são compradas novas e outras são retornadas) são lavadas em uma máquina para evitar o consumo inadequado de água e perdas de garrafas e em seguida são esterilizadas. Além do mais, a cachaça armazenada ainda passa por 5 filtros, dois de 0,5 micra e três de 1,0 micra, evitando assim, possíveis impurezas que podem afetar na qualidade do produto. Após envasadas, as garrafas passam por uma mesa de luz, que tem como finalidade detectar possíveis impurezas na cachaça; em seguida, coloca-se as tampas, o lacre e o rotulo.

Quanto a utilização da água no processo produtivo, vale ressaltar que o engenho está situado em uma região rica em água, e com isso toda a água utilizada no processo produtivo vem dos açudes existentes no próprio sítio do Engenho. A água restante da limpeza é misturada ao vinhoto e armazenada em um reservatório para ser evaporada.

O sistema produtivo da cachaça requer cuidados quanto a destinação dos seus resíduos, pois, embora a única matéria prima utilizada seja a cana-de-açucar, os resíduos gerados podem afetar diretamente o meio ambiente, quando não realizado a destinação adequada dos mesmos. Porém, uma das vantagens que pode ser observada na produção de cachaça é que grande parte dos resíduos podem ser reutilizados no próprio processo produtivo, quando ultrapassado a quantidade de resíduos, os mesmos são vendidos para empresas de outros ramos.

O processo produtivo da cachaça estudada pode ser observado no fluxograma na Figura 2:

Figura 2 . Fluxograma do processo produtivo da cachaça estudada.



Fonte: Elaboração própria (2015). 
$\mathrm{Na}$ produção de cachaça é possível identificar como principais resíduos: a palha - folhas verdes e secas, bainha e ponteiros (SANTOS et al, 2013); o bagaço - resíduo lignocelulósico do processo de extração do caldo da cana-de-açúcar (LIBONI \& CEZARINO, 2012); e o vinhoto ou vinhaça - efluente aquoso rico em matéria orgânica (JÚNIOR, 2013), resultante do processo de destilação. Esses resíduos, se não destinados adequadamente geram sérios impactos ambientais.

Entretanto, de acordo com Santos et al (2012), a palha contribui para a melhoria das propriedades físicas, químicas e biológicas do solo, controle de erosão e plantas daninhas, retenção de umidade e aumento da microbiota do solo. O bagaço, de acordo com Junior (2013) pode ser usado como alimentação animal, bioeletricidade, compostos químicos, etanol de segunda geração e materiais alternativos como fibras e polímeros. Já o vinhoto pode ser utilizado como biogás e fertilizante para o solo via digestão anaeróbica.

Diante do exposto na Figura 2, o engenho estudado realiza as seguintes ações quanto aos seus resíduos gerados: No processo de plantio e colheita, a palha a qual resta da cana retirada para a moagem é deixada no próprio canavial, uma vez que a mesma se transforma em adubo orgânico, enriquecendo assim o solo para futuras plantações. $\mathrm{Na}$ etapa da moagem, o bagaço que é separado do caldo é utilizado para o aquecimento das caldeiras, porém como é gerada uma quantidade muito grande, parte é comercializada para empresas locais para fabricação de ração animal e cama de aviário; enquanto a água utilizada na limpeza da moenda e do decantador vai para um reservatório para ser evaporada. $\mathrm{Na}$ fermentação, como a quantidade de fermento que resta não pode ser mais utilizado, o mesmo é descartado junto com o vinhoto e a água da limpeza para um reservatório específico. A destilação é a etapa do processo que é responsável por gerar maior quantidade de resíduos, quais sejam: vinhoto, cabeça, calda, cinzas e água da produção. O vinhoto, como já citado anteriormente é encaminhado para um reservatório específico, distante dos rios e açudes existente na localidade, evitando assim a contaminação dos mesmos; a cabeça e a calda são misturadas e armazenadas para ser utilizada na higienização, bem como, combustível nos automóveis do proprietário do engenho; as cinzas são utilizadas no plantio da cana como adubo; e a água da produção é utilizada na limpeza. A fase de armazenagem não apresenta a geração de resíduos, pois a cachaça é transportada por uma bomba até o toneis e barris, não existindo desta forma perda do produto. Por fim, no engarrafamento as garrafas - que podem ser quebradas durante a lavagem, ou em qualquer outra situação - são armazenadas e vendidas para a reciclagem; da mesma forma ocorre com o plástico; já o papelão é utilizado para o aquecimento das caldeiras juntamente com o bagaço, porém dependendo da quantidade é descartado no lixo comum.

Sobre os impactos desses resíduos, Nigri et al (2010) destaca que a emissão de $\mathrm{CO}_{2}$ resultante da queima do bagaço e do processo de fermentação, a emissão de material particulado da queima do bagaço e a geração do vinhoto são os principais impactos ambientais do processo produtivo da Cachaça.

Uma forma de otimizar a produção, melhorar os recursos e evitar possíveis perdas é quantificando os insumos utilizados na fabricação do produto, sendo assim, a Tabela 01 mostra a identificação e quantificação dos principais insumos utilizados mensalmente para produzir a cachaça em estudo, bem como, a quantidade destes insumos referente a cada 1 litro de cachaça produzido.

Tabela 1. Identificação e Quantificação dos insumos utilizados na produção da Cachaça

\begin{tabular}{ccccc}
\hline $\begin{array}{c}\text { Principais } \\
\text { Insumos }\end{array}$ & Unidade & $\begin{array}{c}\text { Quantidade } \\
\text { de Insumos } \\
\text { (Mês) }\end{array}$ & Unidade & $\begin{array}{c}\text { Quantidade } \\
\text { de Insumos } \\
\text { para cada } \\
\text { 1 litro } \\
\text { produzido }\end{array}$ \\
\hline Área de & Há & 42 & Há & 0,00114 \\
Plantio & & & & $\mathrm{Kg}$ \\
Cana & Ton & 460 & litros & 12,43 \\
Garapa & Litros & 276.000 & $\mathrm{Kg}$ & 0,16 \\
Bagaço & Ton & 6 & -16 & - \\
Cachaça & Litros & 37.000 & - & \\
\hline
\end{tabular}

Fonte: Elaboração própria (2015).

A área total do Engenho Ipueira é de $500.000 \mathrm{~m}^{2}$, visto que, a área de plantio de cana corresponde a 42 hectares, utilizando $100 \%$ da cana na produção da cachaça, havendo ainda espaço para aumento da plantação, caso seja necessário para suprir a demanda. Para a preparação do solo é utilizado o adubo químico, as cinzas que restam das caldeiras e a palha da cana deixada nos canaviais. Com a área de $420.000 \mathrm{~m}^{2}$ plantados, o engenho consegue moer 460 toneladas de cana por mês, extraindo desta, 276.000 litros de 
garapa, resultando em torno de 37.000 litros de cachaça mensal. Por mês, o Engenho Ipueira consome em média $3.000 \mathrm{kWh}$ de energia elétrica e $80 \mathrm{~m}^{3}$ de água. No processo de destilação, é utilizado em média 6 toneladas de bagaço por mês para aquecimento das caldeiras.

Em relação a produtividade dos insumos, observa-se que para cada litro de cachaça produzido, o Engenho Ipueira utiliza 0,0014 da área plantada e com 12,43 kg de cana, consegue produzir 1 litro de cachaça. Além disso, é utilizado 7,46 litros de garapa para produzir 1 litro de cachaça e são gerados em torno de $0,16 \mathrm{~kg}$ de bagaço nesta produção.

Diante disto, os resíduos gerados pela empresa podem ser analisados tendo como base os níveis da ferramenta da gestão ambiental, a Produção mais limpa.

\section{Produção Mais Limpa: Níveis de Redução de Resíduos na Empresa estudada}

\section{Nível I - Redução na Fonte}

O nível I consiste em reduzir os resíduos na fonte, ou seja, buscar medidas que viabilizem a não geração de resíduos e emissões de poluentes desde o ínício do processo produtivo. Para que isto ocorra, a empresa pode atentar para duas práticas diferentes que abrangem tanto o produto quanto o processo (CNTL, 2003).

No que diz respeito a modificação do produto, o engenho produtor de cachaça em estudo afirma que, como produz cachaça a bastante tempo não buscou desenvolver uma nova concepção do produto ou até mesmo alterar sua composição, uma vez que não há necessidade, haja vista que as técnicas utilizadas já buscam afetar o mínimo possível ao meio ambiente. Além disso, há produção de um único produto não podendo este ser substituído. No entanto, a empresa busca utilizar materiais renováveis como água e energia, fazendo o uso adequado destes sem causar maiores impactos ao meio. Vale ressaltar que utiliza produtos químicos no solo e estes podem afetar a qualidade do produto e provocar impactos ambientais. Ademais, a mesma não utiliza e não tem a perspectiva de utilizar embalagens de materiais reciclados, uma vez que o custo para a aquisição de tais produtos é superior aos utilizados pela empresa. Como a empresa fabrica apenas um produto (cachaça), não há possibilidade do cancelamento da linha de produto, todavia, caso venha acontecer de em determinado período a produção apresentar ameaça ou impacto ao meio ambiente, a empresa afirma que tomaria as medidas coerentes, como: cancelar a produção para analisar e ajustar o processo, de modo a evitar os impactos ao meio ambiente e a sociedade, principalmente à população residente próximo ao engenho.

Em relação a modificação do processo, a empresa em estudo afirma adotar boas práticas operacionais, uma vez que grande parte do seu maquinário são modernos, com exceção da moenda que é do ano 1978. Além de que os funcionários recebem treinamentos para evitar que no processo haja perdas de materiais, evitando assim a geração de resíduos e visando manter o local sempre limpo. O layout foi estruturado de forma adequada para que não ocorra a geração de resíduos, onde os equipamentos são alocados de maneira sequenciada de acordo com cada etapa do processo produtivo. A manutenção desses equipamentos é realizada nos meses de junho e julho e a limpeza destes, do ambiente e dos encanamentos é feita diariamente, visto que, a empresa busca mantêlos sempre limpos, pois além de manter o ambiente agradável, caso ocorra qualquer sujeira por mínima que seja, se cair dentro do produto já compromete sua qualidade, pois cerca de $60 \%$ da qualidade da cachaça está relacionada a limpeza e a fermentação. Em função disso, a empresa utiliza uma boa variedade de filtros e peneiras para evitar que resíduos comprometam a qualidade da cachaça. A empresa busca aperfeiçoar o manuseio operacional, afim de reduzir as perdas de materiais, viabilizando o manuseio do material através de encanamentos, os quais facilita o processamento entre as etapas, além de haver a monitoração constante de cada uma destas etapas para que não ocorra perdas de materiais. No entanto, a empresa não utiliza automação e controles para identificar tais perdas e reduzir riscos de acidente de trabalho, pois todo o maquinário é manual não possuindo desta forma um sensor de perda ou qualquer equipamento que possa reduzir riscos no trabalho.

Diante nisto observa-se que a empresa pouco aplica as técnicas apresentadas no nível I, uma vez que, a mesma requer a modificação do produto ou processo e isto torna-se inviável pois a mesma fabrica apenas um único produto, a cachaça, e para a realização desta não há a possibilidade de alterar o processo produtivo. 


\section{Nível II - Reciclagem Interna}

A reciclagem interna corresponde ao nível II da produção mais limpa, tendo a finalidade de reintegrar ao processo produtivo os materiais e insumos que não foram utilizados no nível 1, seja com a mesma finalidade ou com finalidades diferentes, uma vez que essa prática proporciona a empresa uma diminuição considerável em seus custos, além contribuir para o meio ambiente, evitando que tais materiais e insumos sejam descartados inadequadamente ao meio ambiente.

Sendo assim, observa-se que na empresa em estudo existe alguns resíduos que são impossíveis de evitar, pois são comuns ao processo de fabricação da cachaça de alambique, tais resíduos são: a palha da cana de açúcar, o bagaço, o pó do bagaço decantado, o fermento decorrente do processo de fermentação, o vinhoto e a água proveniente do processo de destilação, a cinzas que restam da queima do bagaço, a "cabeça" e a "calda", os quais também são resíduos do processo de destilação.

Uma das características fundamentais do bagaço é o seu poder calorífico médio de $1850 \mathrm{kcal} / \mathrm{kg}$ (PELLEGRINE, 2002). Toda a energia necessária para o funcionamento da agroindústria vem da geração do vapor da queima do bagaço pelas caldeiras. Para cada tonelada de cana moída são gerados $250 \mathrm{~kg}$ de bagaço com 50\% de umidade (CORTEZ, 1992) e $204 \mathrm{~kg}$ de palha e ponta. Devido as dificuldades de armazenamento e a pouca relevância do bagaço in natura no mercado, a queima tornou-se a principal opção do setor sucroalcooleiro (VIANA, 2011).

A combustão do bagaço gera em torno de 2,5\% de cinzas em relação ao peso inicial de bagaço queimado. No caso das cinzas é possível utilizar como adubo de canaviais ou de outras culturas (OLIVEIRA et al, 2005). É importante ressaltar que para reduzir os impactos das cinzas no meio ambiente, o produtor deve utilizar sistemas de queima através de caldeiras que reduzam a emissão de material particulado na atmosfera. Assim, de acordo com Castro (2001), o nível de poluição do bagaço é baixo, quando comparado com outros combustíveis.

No Engenho em estudo, dos resíduos gerados alguns são reintegrados ao processo de produção, tais como o bagaço, utilizado na queima para aquecer os alambiques; o fermento que permanece no mesmo local para facilitar a fermentação do próximo caldo; a água proveniente do processo de destilação é reutilizada no processo de decantação do caldo; a cabeça e a calda que são misturadas e colocadas em um reservatório para futuramente ser utilizada como álcool combustível para abastecer os transportes da empresa e dos seus proprietários, utilizado também como álcool para fazer a limpeza dos equipamentos.

A empresa não possui uma reserva para o tratamento da água utilizada na limpeza ou em qualquer outra finalidade, esta é descartada em um tanque juntamente com o vinhoto e conduzido a um açude feito pelo próprio engenho para esta finalidade, pois como o vinhoto possui alta periculosidade, a empresa buscou manter este cuidado, evitando o descarte inadequado no meio ambiente, visto que com a construção desse reservatório próprio, torna-se mais rápido o processo de evaporação.

Uma alternativa para o vinhoto é a fertirrigação do solo, sendo utilizada como fertilizante nos canaviais, tendo como resultado o aumento da produtividade agrícola e menores investimentos em fertilizantes químicos (SANTOS et al, 2013), reduzindo com isso, o uso de fertilizantes químicos nas plantações e o impacto do descarte inadequado no meio ambiente.

As garrafas utilizadas como embalagem da cachaça são retornadas após o uso, através de um representante responsável por coletar as mesmas nos estabelecimentos comerciais (bares). Isto ocorre, por que além de tornar o preço de aquisição destas garrafas mais barato, contribui também para o meio ambiente, uma vez que estas poderiam ser descartadas e levariam um bom tempo para se decompor.

Portanto, as técnicas apresentadas no nível II são as mais presentes na organização, uma vez que é realizada a reciclagem de grande parte dos resíduos gerados, exceto o vinhoto. Além disso, com a geração da "cabeça" e da "calda" provenientes do processo de destilação dar-se origem a um novo produto que é o álcool o qual é utilizado tanto na limpeza quanto para o uso futuro como combustível.

\section{Nível III - Reciclagem Externa e Ciclos Biogênicos}

O Nível III é aconselhável quando não é mais possível fazer a reciclagem dentro da organização, levando as práticas da produção mais limpa a serem realizadas fora da empresa, estas podem ser feitas através da reciclagem externa e dos ciclos biogênicos.

A Reciclagem Externa corresponde à reciclagem dos resíduos feita por outras empresas, uma vez que, 
tais resíduos não têm mais como ser utilizado no processo produtivo ou em qualquer outra finalidade da organização. Neste sentido, a empresa estudada afirma que devido a quantidade de bagaço gerado ser muito grande, parte deste é utilizado para aquecer as caldeiras e alambiques, já a outra é armazenado e vendido para criadores de animais, cuja finalidade é a produção de ração, evitando que o bagaço apodreça e seja descartado no meio ambiente.

Os Ciclos Biogênicos estão relacionados à disposição adequada dos resíduos, os quais não puderam ser utilizados de nenhuma forma pelas organizações através da reciclagem externa. Sendo assim, a palha que resta da cana de açúcar é deixada no solo, sendo utilizada como compostagem orgânica, enriquecendo o solo com os nutrientes necessários para a plantação, pois embora o local onde engenho está localizado possui um solo rico em nutrientes, suficientes para que o plantio da cana de açúcar seja produzido, a empresa faz uso desta prática como uma alternativa para melhorar a qualidade da cana de açúcar e, consequentemente a cachaça e assim não descartar o resíduo de forma inadequada ao meio ambiente. As cinzas que restam das fornalhas também são utilizadas com esta mesma finalidade. Vale ressaltar que o vinhoto não é utilizado pela empresa como nutriente para o solo.

Observa-se que o nível III é o segundo mais presente na organização, pois os resíduos que não são utilizados pela empresa, são vendidos, a exemplo do bagaço, dos vidros e plásticos. Do mesmo modo, a palha e as cinzas são utilizadas como fontes de nutrientes para o solo, apresentando-se assim, como uma das técnicas presentes na produção mais limpa que é a compostagem orgânica.

\section{Alternativa Final: Disposição Adequada dos Resíduos}

Embora alguns dos resíduos pudessem ser utilizados pela empresa para adubar o solo, a exemplo do vinhoto que é utilizado pela maioria das empresas do setor através da fertirrigação, este não é utilizado pela empresa em estudo, sendo descartado.

O vinhoto, devido suas propriedades físicas e químicas: alta $\mathrm{DBO}$, baixo $\mathrm{pH}$, açúcares não convertidos, carboidratos não fermentados, leveduras mortas e alto conteúdo de sais minerais, podem causar sérios danos ambientais quando lançados nos rios (SANTOS et al, 2013).
$\mathrm{Na}$ empresa em estudo, o mesmo é armazenado em um reservatório do próprio engenho, a fim de que este juntamente com a água utilizada na limpeza seja evaporado. Portanto, existe a preocupação com a disposição adequada dos mesmos, pois o vinhoto caso seja descartado de forma inadequada ao meio ambiente pode provocar poluição nos rios e açudes presentes próximos ao engenho, e que os mesmoa são fontes de abastecimento para os moradores próximo ao engenho, bem como, para os moradores das cidades vizinhas.

\section{Considerações finais}

O presente estudo teve como principal objetivo identificar as ações da produção mais limpa existente no engenho produtor de cachaça localizado na cidade de Areia - PB, visto que a finalidade desta ferramenta consiste em diminuir os resíduos gerados na fonte, caso isto não seja possível parte-se então para alternativas que possibilitam a reutilização ou descarte adequado dos resíduos gerados.

Na primeira etapa, plantio e colheita o resíduo gerado é a palha que é deixada no solo transformando-se em adubo orgânico; na segunda etapa que é o processo de moagem, o resíduo presente é o bagaço, que é separado do caldo da cana - utilizado tanto como combustível para aquecer as caldeiras, com também para a reciclagem fora da empresa; e a água utilizada para a lavagem da moenda que é descartada em reservatório do próprio engenho. $\mathrm{Na}$ terceira etapa fermentação, o que resta é uma pequena quantidade do fermento natural, descartado junto com a água utilizada na limpeza. A quarta etapa, destilação é a que gera maior variedade de resíduos, pois é nela que é realizada a separação da parte nobre da cachaça com as demais partes, como cabeça e calda, as quais são utilizadas na limpeza dos equipamentos, bem como, armazenadas para serem utilizadas como combustível. Além destas, gera-se uma grande quantidade de vinhoto e este é descartado no mesmo reservatório das águas utilizadas na limpeza, enquanto as cinzas são utilizadas como adubo para o solo. No armazenamento e envelhecimento não são gerados resíduos. E na sexta etapa, o engarrafamento, os resíduos presentes são os vidros, as caixas de papelão e os plásticos, estes são separados e vendidos, sendo o papelão também utilizado para aquecer as caldeiras. 
A partir da identificação dos resíduos gerados no processo produtivo da cachaça, o estudo buscou verificar as praticas de produção mais limpa existente na empresa, separando-as de acordo com os níveis proposto pela ferramenta: Nível de redução na fonte, o qual é prioridade, pois busca-se evitar a geração de resíduo todo o processo produtivo, a partir da intervenção no produto ou no processo. Nível de reciclagem interna, este é aplicado quando não é possível a aplicação do nível anterior, pois o mesmo tem como finalidade a reutilização ou reintegração dos resíduos no processo produtivo. Por último, quando não é possível realizar os dois níveis anteriores, partese então para o nível três, que consiste na reciclagem externa e ciclos biogênicos, a primeira está relacionada a reciclagem dos resíduos realizada por outras empresas, e o segundo são as decisões tomadas pelas organizações em relação a disposição adequada dos resíduos ao meio ambiente.

Nesta perspectiva, no primeiro nível proposto verifica-se de forma menos expressiva a aplicação dos aspectos da produção mais limpa pela empresa. No entanto, quando ocorrem possíveis falhas que possam afetar o meio ambiente, a produção é cancelada e o caso é estudado, afim de evitar reincidência. Por outro lado, o segundo nível é o que está mais presente nas práticas da empresa estudada, pois grande parte dos resíduos gerados é retornado a produção ou utilizados como subprodutos, os resíduos retornados são: a palha, o bagaço, o fermento natural, a água do processo de destilação, as cinzas e o papelão, além desses resíduos outros são transformados em subprodutos, tais como a calda e a cabeça, os quais se transformam em álcool combustível. Por fim, existe também uma boa representatividade das práticas apresentadas no terceiro nível, pois os resíduos tais como o vidro, o papelão, o plástico e parte do bagaço são comercializados com outras empresas ou pessoas que realizam reciclagem, ou seja, a empresa busca alternativa as quais possam favorecer tanto a ela quanto ao meio ambiente. Em relação aos processos biogênicos presente no engenho, pode-se considerar o restante da palha deixada no canavial para se transformar em compostagem orgânica.

A partir deste estudo observou-se que grande parte dos insumos utilizados no processo produtivo parte da principal matéria-prima, a cana de açúcar. A presença das práticas de produção mais limpa, estão relacionadas ao bom aproveitamento para a fabricação da cachaça.
No entanto, existem algumas práticas que não são executadas pelo engenho e poderiam servir como meio de evitar desperdício de alguns resíduos gerados. Tais práticas podem servir tanto para o engenho estudado, quanto para outros produtores de cachaça. Uma medida importante consiste na utilização do vinhoto através do processo de fertirrigação do canavial, pois o mesmo é rico em nutrientes necessários para manter as propriedades do solo e a produção da cana-de-açúcar de qualidade. Essa prática evitaria o armazenamento e o descarte do vinhoto como é atualmente praticado pela empresa, uma vez que o mesmo quando descartado inadequadamente pode afetar o solo e os lençóis freáticos, provocando sérios impactos ambientais.

\section{Referências bibliográficas}

ABRABE. Associação Brasileira de Bebidas Etílicas. Categorias. Disponível em: < http://www.abrabe.org. br/categorias/>. Acesso em: 04 de Agosto de 2015.

AMBIENTE BRASIL. O que é Gestão ambiental? Disponível em: <http://ambientes.ambientebrasil. com.br/gestao/artigos/afinal\%2C_o_que_e_gestao_ ambiental\%3F.html?query=afinal $>$. Acesso em: 04 de Agosto de 2015

BARBIERI, José Carlos. Gestão ambiental empresarial: conceitos, modelos e instrumentos. São Paulo: Saraiva, 2004.

BARROS, Raquel Andrade; MACÊDO, Nívea Marcela Marques Nascimento de. A Competitividade no APL'S de Cachaça na Paraíba. In: Gestão Sustentável no Setor de Cachaça. Waleska Silveira Lira...[et al.]. - João Pessoa: Realize; Editora da UFPB, 2011. p. 46.

BIOSEV. Setor Sucroalcooleiro. Disponível em: $<$ http:/ / ri.biosev.com/biosev/web/conteudo_ pt.asp? idioma $=0 \&$ conta $=28 \&$ tipo $=30884>$. Acesso em: 29 de Julho de 2015.

BORGER, Fernanda Gabriela. Responsabilidade social: efeitos da atuação social na dinâmica empresarial. Tese (Doutorado em Administração) - Programa de Pós-Graduação em Administração, Universidade de São Paulo, São Paulo, 2001.

BRASIL. 1994. Lei no 8.918, de 14 de julho de 1994. Dispõe sobre a padronização, a classificação, o registro, a inspeção, a produção e a fiscalização de 
bebidas, autoriza a criação da Comissão Intersetorial de Bebidas e dá outras providências. Disponível em: <http://www.planalto.gov.br/ccivil_03/LEIS/ L8918.htm>. Acesso em: 30 jul. 2015.

CASTRO, M. A..A luz que vem da cana. Jornal da Cana. Ribeirão Preto, n. 91, p. 38 - 39, jul. 2001.

CNTL. Centro Nacional de Tecnologias Limpas. Implementação de Programas de Produção mais Limpa. Porto Alegre: SENAI, 2003.

CORTEZ, L.; MAGALHAES, P.; HAPP, J.

Principais subprodutos da agroindústria canavieira e sua valorização. Revista Brasileira de Energia. Vol. 2, N o 2. Unicamp, São Paulo, 1992.

DRUN, Kamila C.; GARCIA, Hugney M. Desenvolvimento Sustentável e Gestão Ambiental nas Organizações. Jaciara - Mato Grosso, 2011.

GIL, Antônio Carlos. Como elaborar projetos de pesquisa. São Paulo: Atlas, 2002.

GODOY, A. S. Introdução à pesquisa qualitativa e suas possibilidades. ERA, São Paulo, v. 35, n. 2, p. 5763, Mar-Abri.,1995.

GONÇALVEZ, Gabriela Fernandes. Produção Mais Limpa: Um Estudo de Caso em uma Agroindústria de Cachaça. Relatório de estágio (Bacharelado em Administração), Universidade Federal de Campina Grande, Campina Grande, 2014.

JÚNIOR, S. V. Estratégias Tecnológicas para Biorrefinarias da Cana-de-açúcar. In: Santos, F. A; Colodette, J. L.; Queiróz, J. H. Bioenergia \& Biorrefinaria: cana-de-açúcar \& espécies florestais. Viçosa: Os editores, 2013.

KIPERSTOK, Asher et al. Prevenção da poluição. Brasilia: SENAI/DN, 2002.

\section{LANNA, A. E. L. Gerenciamento de bacia}

hidrográfica: aspectos conceituais e metodológicos. Brasília: Instituto Brasileiro do Meio Ambiente e dos Recursos Naturais Renováveis, 1995. 171 p.

LIMA, A. J. B.; CARDOSO, M. G.; GUERREIRO, M. C.; PIMENTEL, F. A. Emprego do carvão ativado para remoção de cobre em cachaça. Química Nova, v. 29, n. 2, p. 247-250, 2006.

LIBONI, L.B; CEZARINO, L.O..Impactos Sociais e Ambientais da Indústria da cana-de-açúcar. Future Studies Research Journal. São Paulo, v. 4, n. 1, pp. 202 - 230, jan./jun, 2012.
MARCONI, Marina A.; LAKATOS, Eva M.

Técnicas de Pesquisa. São Paulo: Atlas, 2002.

NIGRI, E. M; ROMEIRO FILHO, E; ROCHA, S. D. F.. Cimento tipo Portland: uma aplicação da análise do ciclo de vida Simplificada. In: XXIX Encontro Nacional de Engenharia de Produção. Anais... Salvador, 2009.

OLIVEIRA, C. R.; GARÍGLIO, H. A. A.; RIBEIRO, M. M.; ALVARENGA, M. S. P.; MAIA, F. X. Cachaça de Alambique: manual de boas práticas ambientais e de produção. Convênio de Cooperação técnica SEARA/SEMAD/AMPAQ/FEAM/IMA, 2005.

PELLEGRINI, M. C. Inserção de Centrais Cogeradoras a Bagaço de Cana no Parque Energético do Estado de São Paulo: Exemplo de Aplicação de Metodologia para Análise dos Aspectos Locacionais e de Integração Energética. São Paulo, 2002..

SAKAI, Rogério H. Árvore do conhecimento - Cana-de-açúcar. Cachaça. EMBRAPA, BrasíliaDF, 2010. Disponível em: <http://www.agencia. cnptia.embrapa.br/gestor/cana-de-acucar/arvore/ CONT000fiog1ob502wyiv80z4s473agi63ul.html>. Acesso em: 05 de Agosto de 2015.

SANTOS, F. A; QUEIRÓZ, J. H.; COLODETTE, J. L.; FERNANDES, S. A.; GUIMARÃES, V. M.; REZENDE, S.T. , Potencial da Palha de Cana-deAçúcar para produção de Etanol. Revista Química Nova, Vol. 35, No. 5, 1004-1010, 2012.

SANTOS, F. A; QUEIRÓZ, J. H.; COLODETTE, J. L.;SOUZA, C.J.A.; Nick, C. , Subprodutos da Agroindústria Sucroenergética. In: Santos, F. A; Colodette, J. L.; Queiróz, J. H. Bioenergia \& Biorrefinaria: cana-de-açúcar \& espécies florestais. Viçosa: Os editores, 2013.

VIEIRA, Maria Célia A.; LIMA, Jaldir F.; BRAGA, Natália M. Setor Sucroalcooleiro Brasileiro: Evolução e Perspectivas. 2007. Disponível em: < http://www. bndes.gov.br/SiteBNDES/export/sites/default/ bndes_pt/Galerias/Arquivos/conhecimento/liv_ perspectivas/07.pdf>. Acesso em: 07 de Agosto de 2015.

VIANA, L.F. Potencial energético do bagaço e palhiço de cana-de-acúcar. Lavras, UFLA, 2011. 